\title{
The Determination of Factors Involved in Column-Based Nucleic Acid Extraction and Purification
}

Jun-Jie Poh ${ }^{1,3}$ and Samuel Ken-En Gan ${ }^{1,2,3 *}$

${ }^{1}$ Bioinformatics Institute, Agency for Science, Technology, and Research (A*STAR), 138671, Singapore

${ }^{2}$ p53 Laboratory, Agency for Science, Technology, and Research (A*STAR), 138648, Singapore

${ }^{3}$ Quintech Life Sciences Pte Ltd, 619933, Singapore

\begin{abstract}
DNA extraction methods such as plasmid minipreps, gel, and PCR purifications, are indispensable techniques for genetic manipulations. There are numerous factors that contribute to the efficiency of these processes, which determine the success of complex downstream molecular analytics and diagnostic tests. To study and optimize these factors, we compared our own proprietary buffers to commercially available column-based kits, utilizing their spin columns and protocols. Through systematic substitution of the buffers in the kits with our own proprietary buffers, we selected the highest DNA yielding buffer recipes. Further analysis of the differences between the buffers showed that high concentrations and presence of certain chaotropic agents and cations are necessary for good plasmid miniprep, gel extraction, and PCR purification kits.
\end{abstract}

Keywords: DNA extraction; Gel extraction; PCR purification; Column-based purifications

Abbreviations: E. coli: Escherichia coli; SDS: Sodium Dodecyl Sulfate; TE: Tris-EDTA; OPT: Optimized; HM: Home-Made

\section{Introduction}

The extraction and purification of nucleic acids are commonly used techniques to isolate genetic material from tissues, bacteria, plants, and viruses for important analytical, diagnostic and preparative downstream processes. Amongst these methods, plasmid DNA extraction was the first to be reported [1] using the tedious alkaline extraction protocol. This involved lysozyme treatment to weaken the Escherichia coli (E.coli) cell wall prior to cell lysis and selective denaturation of genomic DNA using sodium dodecyl sulfate (SDS) and sodium hydroxide. Sodium acetate is then used to neutralize the alkaline $\mathrm{pH}$, resulting in the formation of an insoluble network of denatured genomic DNA, protein-SDS complexes and high molecular weight RNA. These complexes were then removed by high speed centrifugation, leaving the desired plasmid DNA in the supernatant [1].

As the protocol was labour-intensive, efforts to simplify the extraction methods gave rise to the development of the "Guanidinium Thiocynate - Phenol - Chloroform" method [2] to separate the various biomolecules through multiple liquid phases [3]. Further developments resulted in doing away with the use of hazardous chemicals (phenol and chloroform) through the use of spin columns for rapid extraction of high purity nucleic acids. Despite simplifying the process through the immobilization of plasmid DNA to the solid phase matrix (i.e. silica), plasmid extraction is still underlined by the need to disrupt bacterial cell walls, denaturation of nucleic acid binding proteins, inactivation of nucleases such as RNases, washing away of undesired contaminants, and elution of desired plasmid DNA.

At the crux, the silica solid phase matrix determines the resultant product purity and yield. For optimal DNA binding, equilibration of these silica columns by $\mathrm{Na}^{+}$is required to break hydrogen bonds for the formation of salt bridges, allowing for spatial interaction with the negatively charged DNA. The silica membrane is then washed with ethanol to remove salts and other contaminants prior to elution of the bound DNA using low ionic strength $(\mathrm{pH} \geq 7)$ buffers [3].
Based on the same principle for plasmid DNA extraction, spin columns had also been used for gel extractions and polymerase chain reaction (PCR) purifications. While these developments have contributed greatly to biomedical research, major developments of these kits are generally largely focussed on membrane material science. To complement this, we have decided to investigate whether the manipulation of chemicals in associated buffers will increase the yields that would enable researchers to tweak their existing commercial kits for improved yields.

\section{Materials and Methods}

\section{Investigation of miniprep buffers}

Proprietary buffers: Proprietary equilibration buffers (P-BK1 and $\mathrm{P}-\mathrm{BK} 2)$; resuspension buffers (P-P1); lysis buffers (P-P2); neutralization buffers (P-P3-1 and P-P3-2); binding buffer (P-W1); wash buffers (PW2-1 and P-W2-2) and elution buffers (P-EB1, P-EB2, and P-EB3) for plasmid extraction with the following ingredients were prepared:

$\begin{array}{lll}\text { P-BK1 } & ---- & \mathrm{NaCl}, \mathrm{MOPS} \\ \text { P-BK2 } & ---- & \mathrm{NaOH} \quad\left(>1 \mathrm{M}\left[\mathrm{Na}^{+}\right] \text {than } \mathrm{P}-\mathrm{BK} 1\right) \\ \text { P-P1 } & ---- & \text { Tris Base, EDTA, RNase A } \\ \text { P-P2 } & ---- & \mathrm{SDS}, \mathrm{NaOH} \\ \text { P-P3-1 } & ---- & \mathrm{C}_{2} \mathrm{H}_{3} \mathrm{KO}_{2} \\ \text { P-P3-2 } & ---- & \mathrm{NH}_{2} \mathrm{C}(=\mathrm{NH}) \mathrm{NH}_{2} \bullet \mathrm{HCl}, \mathrm{C}_{2} \mathrm{H}_{3} \mathrm{KO}_{2}(\mathrm{pH}<\mathrm{P}-\mathrm{P} 3-1)\end{array}$

*Corresponding author: Samuel Ken-En Gan, Bioinformatics Institute, Agency fo Science, Technology, and Research (A*STAR), 30 Biopolis Street, \#07-01 Matrix 138671, Singapore, Tel: 65-6478-8417, 65-6407-0584; Fax: 65-6478-9047; E-mail: samuelg@bii.a-star.edu.sg

Received April 25, 2014; Accepted June 06, 2014; Published June 12, 2014

Citation: Poh JJ, Gan SKE (2014) The Determination of Factors Involved in Column-Based Nucleic Acid Extraction and Purification. J Bioprocess Biotech 4 157 doi: $10.4172 / 2155-9821.1000157$

Copyright: ( 2014 Poh JJ et al. This is an open-access article distributed unde the terms of the Creative Commons Attribution License, which permits unrestricted use, distribution, and reproduction in any medium, provided the original author and source are credited. 


$\begin{array}{lll}\text { P-W1 } & ---- & \mathrm{NH}_{2} \mathrm{C}(=\mathrm{NH}) \mathrm{NH} 2 \cdot \mathrm{HCl} \text {, Isopropanol } \\ \text { P-W2-1 } & ---- & \text { Tris Base, Ethanol } \\ \text { P-W2-2 } & ---- & \text { Ethanol } \\ \text { P-EB1 } & ---- & \text { Tris-Base } \\ \text { P-EB2 } & ---- & \text { Tris-HCl, EDTA } \\ \text { P-EB3 } & ---- & \mathrm{NaCl}, \text { Tris-Base, Isopropanol }\end{array}$

Generic brand A (an "original equipment manufacturer" or "OEM" brand) and generic brand B (well-established brand) buffers were purchased from the commercial vendors.

Culturing of Escherichia coli for miniprep: Luria-Bertani (LB, Biopolis Shared Facilities, BSF, A*STAR) with ampicillin (GoldBio, USA) was used as growth medium. Previously made competent $E$. coli [4] were transformed with ampicillin resistant plasmids bearing antibody genes as previously described [5], and inoculated in LB ampicillin broth in overnight cultures at $37^{\circ} \mathrm{C}$ in a shaking incubator. The plasmids were used for miniprep, gel extractions, and PCR amplification. For comparisons, the same plasmids and bacterial cultures were used.

Establishing the OPT and HM buffers with generic brand A miniprep kit: To establish the best "home-made" (HM) proprietary buffers, we evaluated the solution by systematically displacing the buffers in kit A while following its protocol (Supplementary Material). For the selection of optimized (OPT) buffers, we chose the best buffers between our HM buffers and generic A. Comparisons were performed in triplicate minipreps, standardizing the use of $4 \mathrm{~mL}$ overnight $E$. coli culture, and $40 \mu \mathrm{l}$ of buffer for elution. The HM and OPT buffers were selected based on DNA concentration, and $\mathrm{A}_{260 / 280}$ ratio (Supplementary Data).

Comparison of HM and OPT buffers on generic A and B miniprep kit: Plasmid extraction using HM buffer, OPT buffers, generic $\mathrm{A}$ and $\mathrm{B}$ plasmid extraction kit were each carried out in triplicates. All commercial kits were used according to the manufacturer's recommendations (see Supplementary Material). Comparison of HM and OPT buffers were performed according to the commercial protocol with the exception of varying the buffers on spin columns of both generic $\mathrm{A}$ and $\mathrm{B}$.

\section{Investigation of gel extraction buffers}

Preparation of proprietary buffer for gel extraction: Proprietary gel dissolving buffers (P-QG2, P-QG3) for gel extraction were prepared with the following ingredients:

$$
\begin{array}{lll}
\text { P-QG2 } & ---- & \mathrm{NH}_{2} \mathrm{C}(=\mathrm{NH}) \mathrm{NH}_{2} \bullet \mathrm{HSCN}, \text { Tris-HCl, EDTA } \\
\text { P-QG3 } & ---- & \mathrm{NH}_{2} \mathrm{C}(=\mathrm{NH}) \mathrm{NH}_{2} \bullet \mathrm{HSCN}, \mathrm{C}_{6} \mathrm{H}_{13} \mathrm{NO}_{4} \mathrm{~S} \bullet \mathrm{xH}_{2} \mathrm{O}
\end{array}
$$

Only the gel dissolution buffers were investigated as the other buffers were previously determined in the miniprep comparisons.

Electrophoresis and excision of gel fragment: 1\% TAE agarose gel was used for running the same volume of plasmids in triplicates with $6 \mathrm{x}$ loading dye containing SYBR Green (Quintech Life Sciences Pte Ltd, Singapore). Gel bands were excised with a fixed volume gel cutter and weighed using Mettler Toledo analytical balance. The gel slices typically weighed between $200-300 \mathrm{mg}$.

Comparison of dissolving rate and DNA recovery of generic
$A$ and $B$ gel extraction kits and proprietary buffers: Comparisons between gel extractions buffers from generic $\mathrm{A}$, generic $\mathrm{B}$, and the proprietary buffers (P-QG2, P-QG3) were performed in triplicates. Gel protocols for generic A and B (see Supplementary Material) were carried out according to respective manufacturer's instructions with the exception of standardizing gel dissolution temperature to $60^{\circ} \mathrm{C}$ and elution of DNA at $35 \mu \mathrm{l}$. Gel extractions using proprietary buffers were carried out according to generic A protocol with the exception of varying the ratio of buffer to gel slice to $3: 1 \mathrm{w} / \mathrm{v}$ ratio (according to generic $\mathrm{B}$ protocol). Time taken for the gel slices to dissolve completely were measured with a lab timer and analyzed statistically.

\section{Optimization of PCR purification buffers}

Polymerase chain reaction: PCR reactions of $325 \mu$ l were performed containing $6.5 \mu \mathrm{l}$ of Taq polymerase, $19.5 \mu \mathrm{l} 30 \mathrm{mM} \mathrm{MgCl}$ and $32.5 \mu \mathrm{l}$ of 10X PCR Buffer (Axil Scientific), $26 \mu \mathrm{l}$ of $2 \mathrm{mM}$ dNTPs mix (Quintech Life Sciences), $13 \mu$ l of reverse primer : OriPNrul $\mathrm{R}$ (5'-ATA TCT CGC GAA TGC TGG GGG ACA TGT ACC TC-3'), forward primer OriPNrul F (5'-CAC ACT CGC GAA GGA AAA GGA CAA GCA GCG AA-3'), template plasmid DNA, and $201.5 \mu \mathrm{l}$ of HyClone water (Thermo Scientific, Cat no. SH30538.01). The amplicon ori $P$ is $\sim 1.9 \mathrm{~kb}$. The completed PCR mix was transferred into PCR tubes of $25 \mu \mathrm{l}$ aliquots and carried out in Arktik Thermal Cycler (Thermo Scientific) with the following profile: Initial denaturation at $94^{\circ} \mathrm{C}$ for 5 minutes; 30 cycles of denaturation at $94^{\circ} \mathrm{C}$ for 1 minute, annealing and extension at $71^{\circ} \mathrm{C}$ for 3 minutes; and final extension at $72^{\circ} \mathrm{C}$ for 10 minutes.

Comparisons of PCR purifications of generic $A$ and $B$, and proprietary buffers: Generic A and B PCR purifications and selected proprietary buffers from miniprep (P-W1) and gel extraction (P-QG2) buffers were carried out in triplicates using the respective generic spin columns. A and B PCR purifications were performed according to the respective manufacturer's recommendations (see Supplementary Material). The PCR purification using proprietary buffers were carried out using generic A's protocol, with the exception of using 5:1 volume ratio of buffer to PCR reaction (according to generic brand B protocol).

\section{DNA analysis}

DNA concentration and $\mathrm{A}_{260 / 280}$ ratio were analysed spectrophotometrically using IMPLEN Nanophotometer P330 in triplicates. $1 \%$ TAE agarose gels were used to analyse quantity and quality of plasmid DNA extracted from the minipreps and PCR purifications. $10 \mu \mathrm{l}$ of extracted/purified DNA from the above comparisons were loaded with 6x loading dye containing SYBR Green (Quintech Life Sciences) and analyzed using the RunVIEW electrophoresis apparatus (Cleaver Scientific).

\section{Statistical analysis}

Time taken for the gel dissolution, DNA concentration and $\mathrm{A}_{260 / 280}$ ratio from the nucleic acid extractions were analyzed using One-Way ANOVA and independent T-tests. Significance were deemed when $p<0.05$. All statistical analysis was performed using SPSS 17.0 (IBM).

\section{Results and Discussion}

From the systematic testing, we established a set of optimized (OPT) and completely "home-made" (HM) buffers for nucleic acid extraction and purification kits that are comparable to the two generic brands (A and B) in terms of plasmid yield and purity. Through the step-wise buffer substitution (Table 1), we found that P-P1, P-W2-1 


\begin{tabular}{|c|c|c|c|c|}
\hline Buffer type & $\begin{array}{c}\text { Buffer } \\
\text { comparisons }\end{array}$ & No of expts & $\begin{array}{l}\text { OPT buffer } \\
\text { selection }\end{array}$ & $\begin{array}{l}\text { HM buffer } \\
\text { selection }\end{array}$ \\
\hline \multirow{3}{*}{ Equilibration } & No buffer < GA-BK & 3 of 3 & \multirow{3}{*}{ GA-BK } & \multirow{3}{*}{ P-BK2 } \\
\hline & P-BK1 < GA-BK & 4 of 6 & & \\
\hline & $\mathrm{P}-\mathrm{BK} 2=\mathrm{GA}-\mathrm{BK}$ & 2 of 2 & & \\
\hline Resuspension & P-P1 > GA-A1 & 3 of 4 & P-P1 & P-P1 \\
\hline Lysis & $P-P 2<G A-A 2$ & 3 of 4 & GA-A2 & P-P2 \\
\hline \multirow{2}{*}{ Neutralization } & P-P3-1 < GA-A3 & 3 of 4 & \multirow{2}{*}{ GA-A3 } & \multirow{2}{*}{ P-P3-2 } \\
\hline & P-P3-2 < GA-A3 & 2 of 4 & & \\
\hline Pre-wash & $\mathrm{P}-\mathrm{W} 1=\mathrm{GA}-\mathrm{W} 1$ & 2 of 4 & P-W1 & P-W1 \\
\hline \multirow{2}{*}{ Wash } & P-W2-1 > GA-W2 & 3 of 4 & \multirow{2}{*}{ P-W2-1 } & \multirow{2}{*}{ P-W2-1 } \\
\hline & P-W2-2 < GA-W2 & 2 of 4 & & \\
\hline \multirow{3}{*}{ Elution } & $P-E B 1=G A-E B$ & 2 of 4 & \multirow{3}{*}{ P-EB2 } & \multirow{3}{*}{ P-EB2 } \\
\hline & P-EB2 > GA-EB & 3 of 4 & & \\
\hline & P-EB3 < GA-EB & 3 of 3 & & \\
\hline
\end{tabular}

[DNA] were measured in three separate readings using IMPLEN Nanophotometer P330. Independent T-test was used to determine the statistical significance of the differences between test buffers and generic brand A buffers. Differences in [DNA] were determined when $p<0.05$

Table 1: Comparison between the proprietary buffers and generic brand A miniprep kit buffers using DNA yields.

and P-EB2 were buffers capable of obtaining high DNA yields.

On the equilibration of the spin columns (using generic brand A), the use of GA-BK buffer expectedly gave higher DNA yields than "no buffer" conditions (Table 1). Since the equilibration buffers contained $\mathrm{Na}+$, a salt bridge could be formed, permitting DNA adsorption onto the silica particles [3]. We found that our P-BK buffer yielded less DNA compared to GA-BK (generic A) and P-BK2 buffer, as the latter two buffers had higher concentrations of $\mathrm{Na}+$ (more than double the molarity), this demonstrates that high $\left[\mathrm{Na}^{+}\right]$allowed for effective equilibration.

Regarding the neutralization buffers, P-P3-2 buffer yielded significantly higher DNA than the P-P3-1 buffer $(t(70)=2.121$, $p=0.038$, see Table 1). Since both P-P3-1 and P-P3-2 buffers acted to neutralize the alkaline lysis buffer, the resultant $\mathrm{pH}$ after neutralization would be lower for P-P3-2 due to its stronger acid component, supporting previous reports that lower $\mathrm{pH}(<7)$ facilitated better DNAsilica adsorption [3].

Amongst the wash buffers, P-W2-1 buffer had the highest DNA yield while P-W2-2 buffer had the lowest yields. From studying buffer recipes, we propose that the higher salt content in P-W2-1 increased the stringency of the column washes, removing nucleases more efficiently and preventing DNA degradation.

On the comparison of the elution buffers, P-EB2 was significantly better than P-EB1 $(t(64)=2.19, p=0.032)$. As the only elution buffer with EDTA, $\mathrm{Mg}^{2+}$, a co-factor in many nucleases [6] would have been chelated. Since P-EB-2 also had a hundred-fold more Tris than P-EB1, there would be better $\mathrm{pH}$ buffering without producing free radicals that would otherwise speed up the auto-catalytic activity of DNA [6]. Comparatively, P-EB3 showed the lowest DNA yields (even below that of generic A buffer). Since isopropanol was a component, it is likely that DNA precipitation may have occurred, lowering yields.

As generic $\mathrm{A}$ and $\mathrm{B}$ buffer recipes were not known to us, we were unable to discuss the likely factors that contributed to the different DNA yields observed for the resuspension, lysis and pre-wash buffers (P1, P2, and $\mathrm{W} 1$, respectively).

With the HM and OPT buffer components determined, benchmarking was performed against the generic brand $\mathrm{A}$ and $\mathrm{B}$ miniprep kits. Generic brand B was specifically picked due to the company's reputation in these kits. Our comparisons (Figure 1) found that the use of HM buffers on generic A columns did not perform better than generic A buffers. This was expected since some HM buffers (equilibration, lysis and neutralization) gave poorer yields than generic A counterparts (Table 1).

When OPT buffers were used on generic A spin columns (top panel of Figure 1, lane 2), and HM buffers on generic B spin columns (top panel of Figure 1, lane 6), we found that OPT buffers had higher yields than both generic A and B kits when using their respective buffers (top panel of Figure 1, lanes 1 and 4, respectively). HM buffers on generic B spin columns had the highest yields despite yielding the least DNA on generic A spin column. This shows that generic B spin columns had superior DNA binding capability, and that OPT buffers would give the best yields since they outperformed generic A buffers, which were in turn, superior to HM buffers (top panel of Figure 1). As the exact differences between generic $A$ and $B$ spin columns were unknown to us, we are unable to discuss this further.

On the fastest gel dissolution time, P-QG2 buffer showed the fastest average rate $(211$ secs), followed by P-QG3 (220 secs), generic B QG (234 secs), and generic A G-G1 buffer (354 secs; see Figure 2). ANOVA tests showed that the time differences were significant $(F(3,32)=$ $129.86, p=0.000$ ).

On DNA recovery, P-QG2 had better or similar DNA recovery compared to both generic A and B buffers, respectively (Table 2), whereas P-QG3 buffer had lower yields than generic brand B kit despite being comparable to brand A. Investigations between our two proprietary buffers showed that P-QG2 had higher concentrations of guandidine thiocyanate (by almost $1 \mathrm{M}$ ). As a chaotropic agent that removes DNA binding proteins [7], the higher concentration

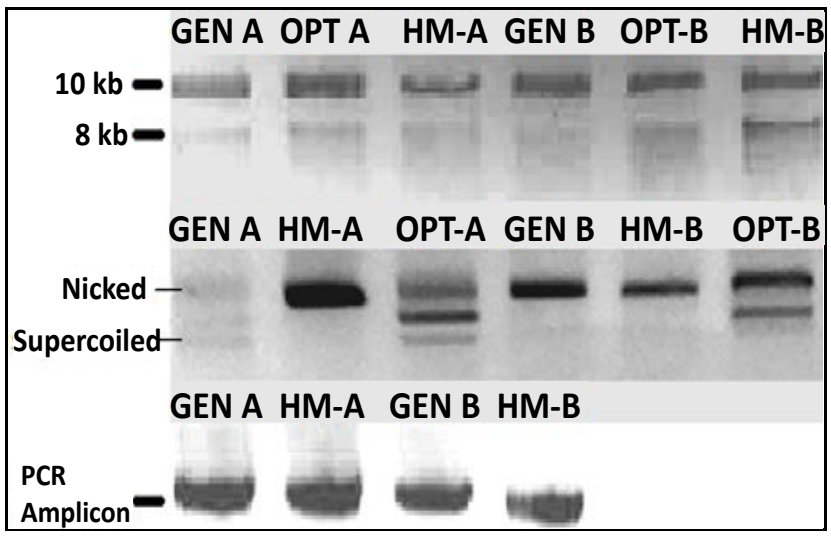

Figure 1: Final comparison of generic brands A, B, HM and/or OPT miniprep (top), gel extraction (middle) and PCR Purification (bottom) protocols.

GEN A = Nucleic acid extractions using generic A kits;

$\mathrm{HM}-\mathrm{A}=$ Nucleic acid extractions using generic $\mathrm{A}$ spin column with $\mathrm{HM}$ buffers OPT-A = Nucleic acid extractions using generic $A$ spin column with OPT buffers GEN $B=$ Nucleic acid extractions using generic $B$ kits:

$\mathrm{HM}-\mathrm{B}=$ Nucleic acid extractions using generic $\mathrm{B}$ spin column with $\mathrm{HM}$ buffers: OPT-A = Nucleic acid extractions using generic $B$ spin column with OPT buffers 10uL of DNA extracted were mixed with $6 x$ loading dye and loaded on a $1 \%$ TAE agarose gel. All DNA concentrations determined using IMPLEN Nanophotometer P330 were signifcantly different between groups in One-Way ANOVA. $F(5,12)=109, p=0.000$, for miniprep; $F(5,12)=170.691, p=0.000$ for gel extraction; and $F(3,8)=1250.141, p=0.000$, for PCR Purification Please see supplementary data for nanospectrophotometer readings. 
of guanidine would have aided in better adsorption to the silica gels. Being similar to other chaotropic agents (e.g. potassium or sodium iodide), which are necessary for dissolving agarose gels [8], the higher concentrations of guanidine thiocyanate would also dissolve the agarose quicker. Thus, on the basis of timing and yields, P-QG-2 was chosen as the optimal buffer.

For PCR kits, we compared only the PCR binding buffers i.e. the optimized P-W1 and P-QG2 with generic A and B buffers. ANOVA tests showed significant differences between the DNA recovered, $F$ $(5,48)=261.72, p=0.000$. It was observed that using generic $\mathrm{B}$ column, buffer P-W1 (P-W1-B in Figure 3A) obtained the highest DNA recovery, almost up to $30 \mathrm{ng} / \mu \mathrm{L}$. On the contrary, the same $\mathrm{P}-\mathrm{W} 1$ buffer in generic A column yielded only slightly above $20 \mathrm{ng} / \mu \mathrm{L}$, thus supporting previous miniprep observations that generic B spin columns were superior with respect to DNA binding. Normalizing the spin columns by comparing P-W1 on both A and B spin columns, buffers of both generic brands would generate similar yields.

Electrophoresis of the purified PCR products using the different

\begin{tabular}{|c|c|}
\hline Buffer comparisons & Total no of expts \\
\hline P-QG2 $>$ Generic $A$ & 3 of 3 \\
\hline P-QG3 $=$ Generic A & 3 of 3 \\
\hline P-QG2 $=$ Generic $B$ & 2 of 3 \\
\hline P-QG3 $<$ Generic $B$ & 3 of 3 \\
\hline
\end{tabular}

Gel Extractions using P-QG2 and P-QG3 were carried out using generic brand A protocol (see Supplementary Material) with the exception of varying the gel dissolving buffer GA-G1.

DNA concentrations were measured in three separate readings using IMPLEN Nanophotometer P330. Independent T-tests were used to determine the statistical significance of the differences in DNA recovered. Differences were deemed significant when $p<0.05$

Table 2: Comparison of DNA yields in 3 independent gel extraction experiments using P-QG2 and P-QG3 buffers compared against generic brands $A$ and $B$ buffers using their respective kits and protocols.

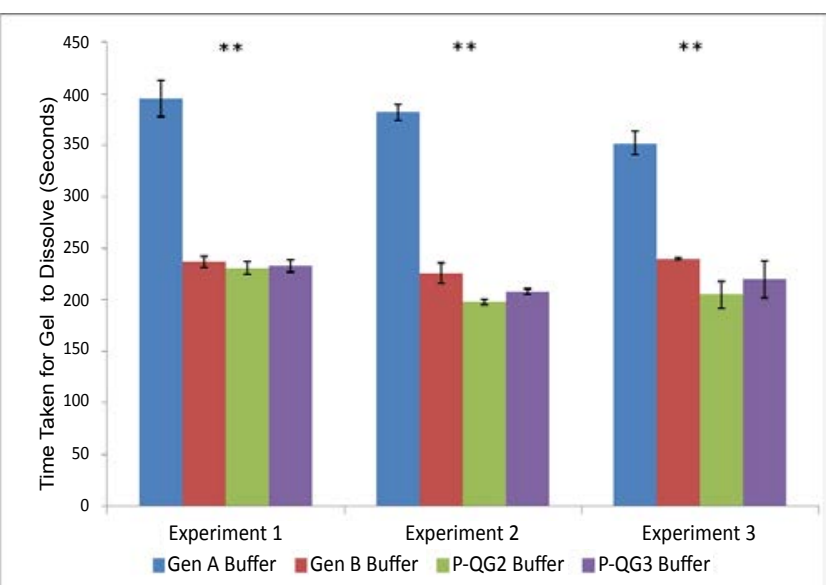

Figure 2: Comparison of time taken for excised gel fragments to dissolve completely using generic brand A and B gel dissolving buffers, P-QG2 and P-QG3 buffer.

Bar chart showing the means and standard errors of the time taken for excised gel fragments to dissolve completely using gel dissolution buffers of generic $A$ and $B, P-Q G 2$ and $P-Q G 3$ in 3 independent experiments. Gel extractions using P-QG2 and P-QG3 were carried out using brand A's protocol (see Supplementary Material) with the exception of varying the gel dissolution buffer GA-G1. Time taken for each excised gel to dissolve completely were determined with a timer. Gel fragments weighed around 200-300 mg and respective buffers used to dissolve gel were aliquoted accordingly. ${ }^{*} p<0.05$ ${ }^{* *} p<0.001$ for the One-Way ANOVA.

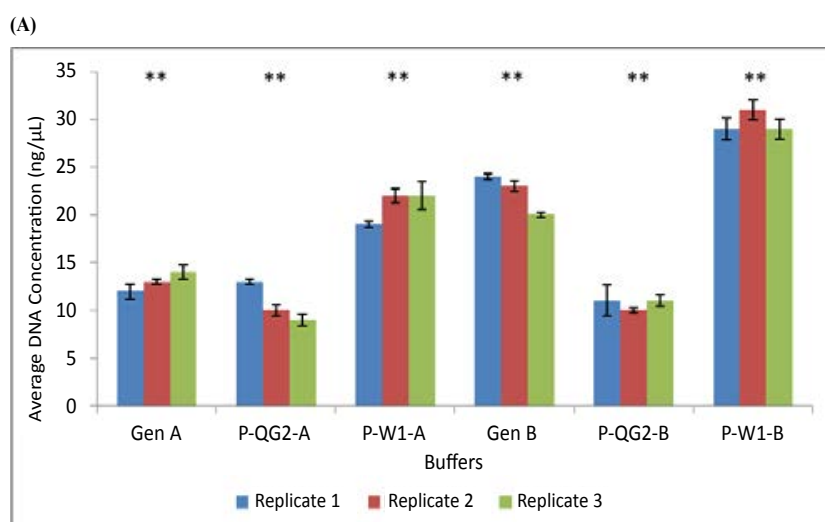

Figure 3A: Comparison of the DNA recovered using P-QG2, P-W1, generic brands A and B's PCR purification buffers.

Bar chart showing the means and standard errors of the DNA recovered using various buffers. P-QG2-A and P-W1-A buffer testing were carried out using brand A's protocol (see Supplementary Material). On the other hand, P-QG2-B and P-W1-B buffers were performed on brand B's spin column (without P-BK) DNA concentrations were determined by IMPLEN Nanophotometer P330 in three separate extractions measured in triplicates.

Gen $A=$ PCR Purification using generic A PCR Purification Kit

P-QG2-A = PCR Purification using generic A column with P-QG2 buffer

P-W1-A = PCR Purification using generic A column with P-W1 buffer;

Gen $B=$ PCR Purification using generic $B$ PCR Purification Kit;

$P-Q G 2-B=P C R$ Purification using generic $B$ column with $Q G 2$ buffer;

$\mathrm{P}-\mathrm{W} 1-\mathrm{B}=\mathrm{PCR}$ Purification using generic $\mathrm{B}$ column with $\mathrm{P}-\mathrm{W} 1$ buffer.

${ }^{*} p<0.05 ;{ }^{* *} p<0.001$ for the ANOVA tests comparing the DNA recovered.

spin columns revealed two distinct bands that corresponded to the OriP product and primer dimers. Interestingly, $\mathrm{P}-\mathrm{W} 1$ removed primer dimers when used on generic A columns but not on generic B columns. This was likely due to the higher binding capability of generic $B$ columns. Nonetheless, P-QG2 was clearly the better buffer as it yielded the highest intensity band regardless of the spin column used (Figure $3 \mathrm{~B}$ and $3 \mathrm{C})$.

Analysis of the P-QG2 and P-W1 recipes found that higher concentrations of guanidine (by $\sim 1 \mathrm{M}$ in P-QG2) resulted in better purification, which we propose to result from the release of polymerases from DNA, allowing their adsorption to the silica.

As a final comparison, we carried out trials comparing the full set of HM buffers and OPT buffers against both generic A and B (Figure 1). As can be observed, OPT buffers had the best yields regardless of the columns used, with HM buffers comparable to the commercial brands $\mathrm{A}$ and $\mathrm{B}$.

\section{Conclusion}

The findings of the study allowed us to rely on more cost-effective columns without compromising experiments. Extending beyond the kits tested, the factors of these buffers also underline processes such as midi, maxi and giga scale DNA extractions, allowing labs to optimize their own cost-effective reagents by the addition of important chemicals to their existing buffers or kits (e.g. adding a $\mathrm{Na}^{+}$column equilibration step to existing commercial kits). Through detailed analysis of buffer constituents, we were able to validate the importance of:

1) $\mathrm{Na}^{+}$concentrations in column equilibration.

2) Importance of strong acids for low $\mathrm{pH}$ in the neutralization of cell lysis buffer. 
Citation: Poh JJ, Gan SKE (2014) The Determination of Factors Involved in Column-Based Nucleic Acid Extraction and Purification. J Bioprocess Biotech 4: 157 doi: 10.4172/2155-9821.1000157

(B)

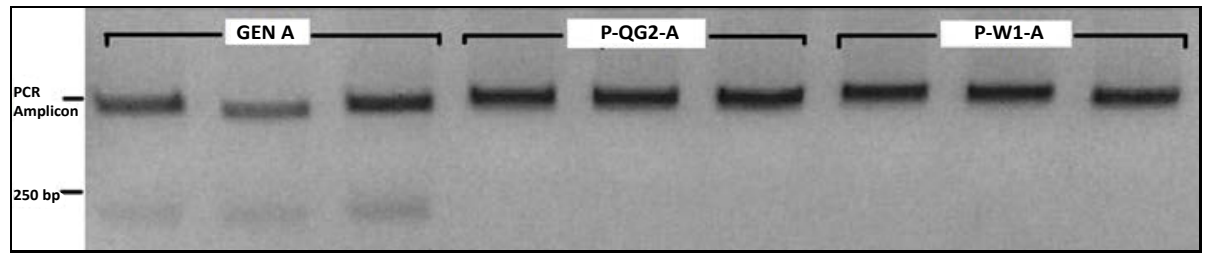

(C)

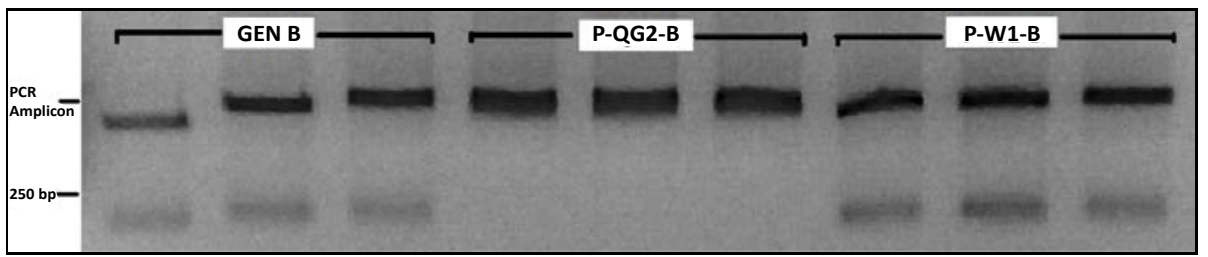

Figure 3B and 3C: Comparison of the P-QG2 and P-W1 with generic brand A and B PCR purification kits.

(B) Comparisons of P-QG2 and P-W1 buffers were performed using generic $A$ spin columns.

(C) Comparisons of P-QG2 and P-W1 buffers were performed using generic B spin columns.

10uL of purified PCR DNA were mixed with $6 x$ loading dye and loaded on a $1 \%$ TAE agarose gel using RunVIEW by Cleaver Scientific. Samples were processed from the same PCR reaction for consistency.

3) High salt for higher stringency in column washes.

4) Tris and chelating agents to remove nuclease cofactors and $\mathrm{pH}$ buffers that would not generate free radicals.

5) High presence of chaotropic agents for faster gel dissolution and removal of interfering proteins for both gel and PCR kits.

\section{Acknowledgement}

We would like to thank Sir David Lane, Chandra Verma, Peck-Ting for their administrative support, without which the work would not be possible. We also thank Mr Keane MJ Lim for assisting in the formatting of the article. This work is mainly funded by Quintech Life Sciences Pte Ltd, with support from the Joint Council Office, Agency for Science, Technology, and Research, Singapore.

\section{Competing Interests}

This work was commissioned by Quintech Life Sciences Pte Ltd to explore the factors to making better buffers, which may be made commercially available. There are no other competing interests.

\section{References}

1. Birnboim HC, Doly J (1979) A rapid alkaline extraction procedure for screening recombinant plasmid DNA. Nucleic Acids Res 7: 1513-1523.

2. Chomczynski P, Sacchi N (1987) Single-step method of RNA isolation by acid guanidinium thiocyanate-phenol-chloroform extraction. Anal Biochem 162 156-159.

3. Tan SC, Yiap BC (2009) DNA, RNA, and Protein Extraction: the Past and the Present. Journal of Biomedicine and Biotechnology 2009: 1-10.

4. Chan WT, Verma CS, Lane DP, Gan SK (2013) A comparison and optimization of methods and factors affecting the transformation of Escherichia coli. Biosci Rep 33.

5. Gan S, Hunt J, Marsh P, Beavil A, Harries H (2009) The design and optimisation of a transient expression system for the rapid expression of human immunoglobulin $\mathrm{E}$.

6. Gerstein AS (2004) Molecular Biology Problem Solver: A Laboratory Guide John Wiley \& Sons, New York, USA

7. Boom R, Sol CJA, Salimans MMM, Jansen CL, Wertheim-Van Dillen P, et al. (1989) Rapid and Simple Method for Purification of Nucleic Acids. J Clin Microbiol 28: 495-503.

8. McPherson M, Moller S (2006) Purification and Cloning of PCR Products, PCR Taylor and Francis Group, New York, USA. 